\title{
Critical Analysis of Mitral Valve Prolapse Syndrome below Forty Years
}

\author{
Dr.V.UshaPadmini.MD ${ }^{1}$, Dr.Manohari Ramachandran, $\mathrm{MD}^{2}$, Dr.Subodh ${ }^{3}$, \\ ${ }^{1}$ Senier Assistant Professor, Department of General Medicine, Coimbatore Medical College \& Hospital. \\ ${ }^{2}$ Professor, Department of General Medicine, Coimbatore Medical College \& Hospital. \\ ${ }^{3}$ Post Graduate In General Medicine, Department of General Medicine, \\ Coimbatore Medical College \& Hospital.
}

\begin{abstract}
Mitral valve prolapsed is a clinicopathological entity characterized by billowing or prolapsed of one or both leaflets into the left atrium during systole which seems to arise from an alteration in leaflet and chordal structure.MVP is a primary dominantly inherited condition. Midsystolic click and late systolic murmur that moves dynamically with various postural maneuvers is the hall mark of this syndrome. Conventionaly as a most common congenital heart disease,next to Bicuspid aortic valve.It is common in females, mostly asymptomatic, complication like progressive Mitral Regurgitation, infective endocarditis,congestive cardiac failure,sudden cardiac death also seen.
\end{abstract}

\section{Introduction}

This study is about critical analysis of various clinical presentations, signs and symptoms and echocardiograpdic findings and complications of Mitral valve prolapse syndrome below 40 years and its incidence regarding age and sex among the study group.

1. To asses the Age and Sex incidence.

\section{Aim Of The Study}

2. To study the presentations, variable signs and ECHO findings.

3. And to find the complication of Mitral Valve Prolapse syndrome.

\section{Materials And Methods}

This study was conducted in Govt.hospital,Coimbatore Medical college and hospital,Coimbatore. The study was done for about a period of one year from March 2014 to March 2015 .The patients who were refered for cardiac symptoms to cardiology out patients department from medical units and paediatric departments are included in this study. Patients below the age of forty;females , males ,children were included; Middle and lower class people from various background.

All the patients are fully questioned for detailed history. In addition to general symptoms, cardiac symptoms like chest pain ,palpitations, dyspnoea,syncope, focal neurological deficits werecery carefully evaluated. Past history was taken to ruleout the existence of hypertension,congenital heart disease,Rheumatic fever,syphilis, , congestive heart failure.Treatment history like any operation, previous admission, drugs taken for any cardiac illness taken;family history mainly focussed to assess the $1^{\text {st }}$ degree relatives with symptoms were taken.If the relatives are available they also examined.

Next careful general examination was done to find pectus excavatum,scoliosis,reduced anteroposterior diameter, straight thoracic spine, features of Marfan syndrome.Blood pressure both arms were taken. Lying and standing BP also checked. Ll cases were examined carefully for the evidence of cardiac failure/associated anomalies of the heart,focal neurological deficits,infective endocarditis, arrhythemias. Auscultation oh heart was performed in lying supine, left lateral position and standing. Other maneuvers like leg raising,valsalva, after isometric exercise also performed. Efforts were made to find pulmonary hypertension/ASD/AR/TR/Dissection, Aneurysm of aorta and to differentiate HOCM.

Blood test /urine tests were done for Diabetes Mellitus / Renal disease. Haemogram to rule out anaemia was done. $\mathrm{X}$ chest postero anterior view was taken all patients to asses cardiac size,pulmonary vascularity, aortic morphology thoracic anomalies and mitral annular calcification. All 12 lead ECG was done to find various changes( like ST segments, T Wave changes, Ventricular premature beats)that occur in MVPs.

Echocardiography wasdone in all these cases to confirm the diagnosis. Both M-mode and two Dimensional ECHO were done. 2D Echo was done in all four views mainly parasternal long axis view. Redundancy or excess valve tissues at the valve ring were noted. Eventhough prolapsed of the other valves like tricuspid,aortic valve can occur, concentrated only on mitral valve. 
About 2000 cases were attended in cardiology department, during the period of March 2014 to March 2015.

\section{Observation}

From March 2014 to March 2015, about 2000 new cases were attended in our cardiology department for various cardiac problems. Out off these 102 cases were found to be mitral valve prolapse syndrome. In this , eighty cases were primary mitral valve prolapse syndrome.So, the incidence of Mitral valve prolapsed syndrome is 4 percent. Common in females. Age group between 10-30 years.

All the eighty patients presented with symptoms. This however is due to the fact that the study was done in the Cardiology department where refered cases alone are seen. Some cases incidentally found (17) Mitral valve prolapsed syndrome. If they have symptoms in the history,also included in this study.

No past history of hypertension, Ishemic heart disease,Diabetes Mellitus,infective endocarditis in these cases. No significant family history suggestive of MVPs in the $1^{\text {st }}$ degree relatives except in five cases ( 6 percent).

\section{Age Distribution}

\begin{tabular}{|l|l|l|l|l|l|l|l|}
\hline $1-10$ years & \multicolumn{2}{l}{$11-20$ years } & \multicolumn{2}{l|}{$21-30$ years } & 31-40 years \\
\hline \hline Male & Female & Male & Female & Male & Female & Male & Female \\
\hline 2 & 4 & 13 & 27 & 11 & 14 & 6 & 3 \\
\hline
\end{tabular}

\begin{tabular}{|l|l|l|}
\hline Category & Total number of cases & Percentage \\
\hline Below 20 years & 46 & $57.5 \%$ \\
Above 20 years & 34 & $43.5 \%$ \\
\hline
\end{tabular}

Sex Distribution

\begin{tabular}{|l|l|l|l|}
\hline CATEGORY & NO OF CASES & TOTAL & PERCENTAGE \\
\hline FEMALE & & & \\
Below 20 years & 31 & 48 & $60 \%$ \\
Above 20 years & 17 & & \\
\hline MALE & & 32 & $40 \%$ \\
Below 20 years & 15 & 17 & \\
Above 20 years & 17 & \\
\hline
\end{tabular}

\begin{tabular}{|l|l|l|}
\multicolumn{3}{l}{ Symptoms Distribution } \\
\hline SYMPTOMS & CASES & PERCENTAGE \\
\hline CHEST DISCOMFORT & 68 & $80.50 \%$ \\
PALPITATIONS & 56 & $70 \%$ \\
DYSPNOEA & 12 & $15 \%$ \\
SYNCOPE & 17 & $21.25 \%$ \\
NEUROLOGICAL DEFICIT & 3 & $3.5 \%$ \\
\hline
\end{tabular}

Out of these 80 cases $65 \%$ of the patients (52 cases) were presented with more than one symptom.

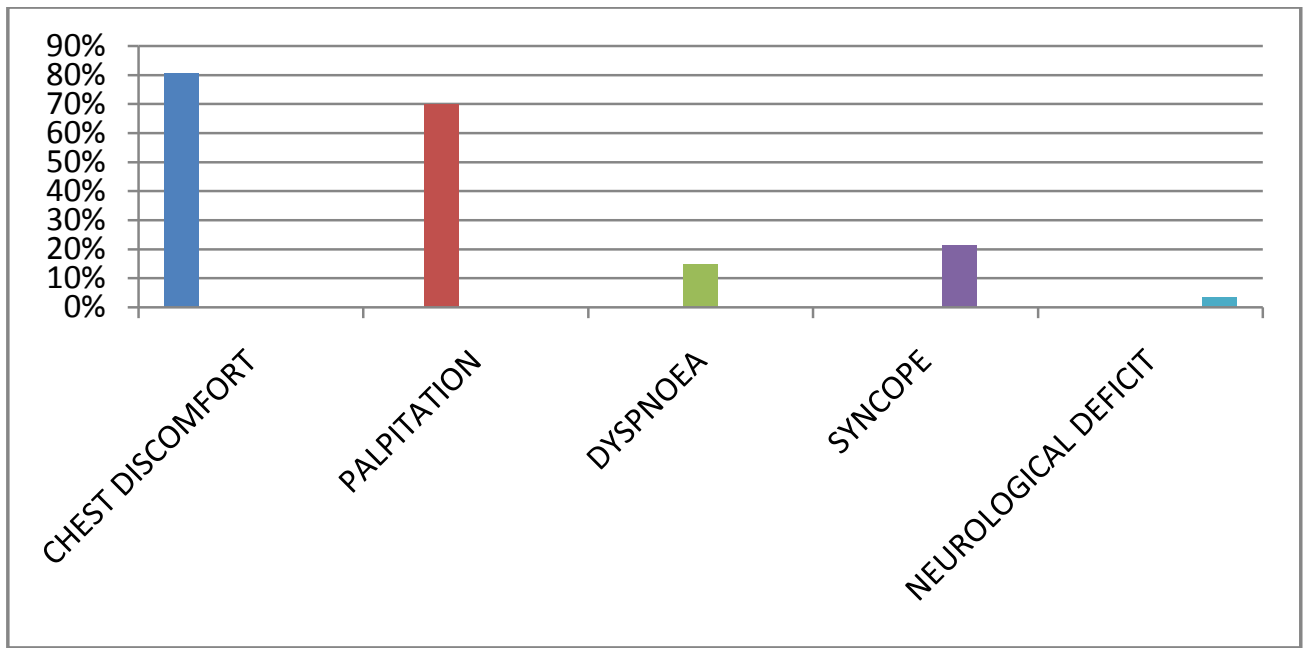

\section{Clinical Findings}

Clinical examination showed findings in favour of Marfan's syndrome in 5 cases. Narrow Anteroposterior diameter in 5 cases. Scoliosis 1 cases,pectus excavatum 5 cases. Total number of cases with chest wall abnormalities are 12 cases (13.5 percent). 


Various Signs
\begin{tabular}{|l|l|l|}
\hline SIGNS & CASES & PERCENTAGE \\
\hline Total cases with click(with or without murmur) & 57 & 71.25 \\
Total cases with murmur(with or without clicks) & 41 & 51.5 \\
Click alone & 39 & 48.75 \\
Murmur alone & 23 & 28.75 \\
Both present & 18 & 22.5 \\
\hline
\end{tabular}

Types Of Murmur Murmur Changes With Dynamic Auscultation

\begin{tabular}{|l|l|l|}
\hline Murmur 41 Cases & Cases (Of The 41) & Percentage \\
\hline Late Systolic Murmur & 24 & 58.5 \\
Mid Systolic Murmur & 14 & 31.5 \\
Holo Systolic Murmur & 3 & 7 \\
& & \\
\hline
\end{tabular}

Congestive cardiac failure (CCF) $\quad 10 \%$

Infective endocarditis (IE) $\quad 1.25 \%$

Stroke

$3 \%$

$\mathrm{IE}+\mathrm{CCF}+\mathrm{STROKE}$

\section{Age and Sex:}

\section{Conclusions}

In our study ,the incidence of mitral valve prolapsed syndrome is 4 percent It is more common in young females than males. The incidence is $67.5 \%$ in the age group 1-20 years. Maximum incidence of mitral valve prolapsed syndrome is in 10-20 years age group.Familial incidence is uncommon in our study.

\section{Clinical Presentation}

All the cases are primary mitral valve prolapses. All the patients presented with symptoms. Chest pain is the most common symptom $80.5 \%$ followed by palpitation $70 \%$.

Click is the commonest sign. It is the most diagnostic of all.

Murmur may be mid or late or holo systolic. It may be musical or non musical (Honking/whooping). The click and the murmur that move dynamically with postural maneuvers is diagnostic of Mitral Valve prolapsed syndrome.

In ECG,T wave changes is a common finding. Appearance of Question mark turned 90 degree clockwise or "HAMMOCK" appearance of C-D segment in M-mode is the hallmark of MVPs,in Echocardiogram. The prolapsed may be late or pansystolic in 2D ECHO. ECHO is also useful in the assessment of complications.

\section{Complications}

Congestive cardiac failure was present in $10 \%$ of cases. Thromboembolism was noted in $3.5 \%$ of cases and $1.25 \%$ of cases are presented with infective endocarditis.

All the above complications are common in females than males.

This shows, in every patients particularly young people, with unexplained ventricular premature contraction/stroke/congestive cardiac failure, We must suspect MVPs and do dynamic auscultation, Echocardiography.

[1]. Hurst's THE HEART 12 th edition

\section{Bibliography}

[2]. Cardiovascular Medicine by James T.Willerson,M.D

[3]. HEART DISEASE: A text book of cardiovascular Medicine by EUGENE BRAUNWALD 9 th edition

[4]. Harrison's principles of Internal Medicine, $18^{\text {th }}$ edition

[5]. Grays Anatomy

[6]. Echocardiography by Harvey Feigenbaum M.D. $7^{\text {th }}$ edition

[7]. Barlow J.Pocock W..MVP, Specific Billowing mitral leaflet syndrome or an insignificant non ejection click.American heart .97;277-1979.

[8]. Edwards 's J.Floppy MVPs. Cardiovascular clinic 1;249 1976 (pathology)

[9]. CRAWFORD M.H, O'ROURKE : The systolic click murmur syndrome-clinical Diagnosis and management.Curr probi cardiol.

[10]. Levine RA,Triuiai,Weyman A.E ., The relationship of mitral annular shape to the diagnosis of MVPs.

[11]. Weissman NJ Shear MK, Devereavx RB contrasting patterns of Autonomic dysfunction in patients with MVP and panic Attaks American Journal of Medicine.

[12]. Boudoulas H.Kolibash AJ.King B.D .MVP and MVPs: a diagnostic classification and pathogenesis of symptoms AM heart journal

[13]. Prevalence of MVP by 2D ECHO - British heart journal.

[14]. Rueda B, and Arvan S, The relationship between clinical and echocardiographic finding in MVP, Herz,

[15]. Pomerance A.Balloning ( Mucoid degeneration) deformity of atrioventricular valve. British heart journal. 